\title{
Burdened in Business: Pacific Early Career Academic Experiences with Promoting Pacific Research Methodologies in the Business Academy
}

\author{
Sisikula Sisifa, 'Ilaisaane Fifita
}

\begin{abstract}
Ongoing calls to indigenise the academy renew debate regarding the value and significance of Pacific and Indigenous philosophies and methodologies. This paper contributes to this conversation by reflecting on our experience as Tongan women and early career academics promoting the utility of Pacific methodologies such as talanoa within business research in Aotearoa. We examine the constraints on and drivers to adopting talanoa in our respective fields to argue that institutional demands and limited Pacific capacity within the business space restrict our ability to work towards legitimising talanoa and drive future-focused directions in research. These factors hinder our ability to actively contribute to the agenda of indigenising the business academy.
\end{abstract}

\section{Introduction}

In recent decades, the encouragement of methodological and philosophical pluralism has promoted research approaches that are responsive to previously marginalised voices. ${ }^{1}$ Indigenous people worldwide have been overresearched, with little consideration given to culturally appropriate methods of engagement. ${ }^{2}$ Hence, undertaking research that ensures culturally appropriate processes for engaging with Indigenous people is crucial. Although Indigenous research methodologies have always existed, it is only recently that Indigenous scholars have been able to challenge Western hegemony within the university. ${ }^{3}$ Indigenous participants in research often note the disconnect in using Western research approaches to explore Indigenous contexts and perspectives. ${ }^{4}$ The use of Indigenous research methodologies directly connects Indigenous participants' worldviews with theoretical, epistemological, methodological, conceptual and ethical frameworks used in research. Different Indigenous research methodologies and methods have been developed around the world to represent and align more accurately with distinct Indigenous voices.

Some of these methodologies are well established. Others, like Pacific research methodologies and methods, continue to develop as more Pacific scholars engage with this important work. Disciplinary norms often shape methodological choice and are reinforced by the expectations and standards regarding methodologies that are publishable. For instance, some of the most influential management and marketing journals typically prioritise experimental methods that are well established in Western research. To increase the probability of our work being published in these journals, we are encouraged to adopt the preferred Western, positivist research methods. However, positivist research, the preference in many top tier journals, does not align well with Indigenous research methods. For example, the Pacific research method or methodology of talanoa is more congruent with an interpretivist paradigm. Furthermore, Indigenous knowledge is often conveyed in narrative or metaphorical language. Hence, many Indigenous scholars face barriers to using Indigenous research methodologies while adhering to publishing requirements in the more influential journals within their discipline. It has been our experience in the business space that

Journal of New Zealand Studies NS33 (2021), 70-82 https://doi.org/10.26686/jnzs.iNS33.7383 
such journals often position Indigenous research paradigms as exotic, engage with only in tokenistic fashion, and privilege conventional Eurocentric frameworks for generating knowledge.

Engaging in Indigenous research approaches is also important because it recognises the ontological authority of Indigenous elders and the practices in which their knowledge is produced. ${ }^{4}$ Despite the established history and wealth of Indigenous knowledge, scholars have struggled to establish a firm recognition of Indigenous knowledge and research methodologies in the business discipline. A key tension across all disciplines in using Indigenous methodologies is that Indigenous research approaches are often not delineated and defined on their own but defined and justified in relation to Western research paradigms. ${ }^{5}$ This challenge has contributed to the limited extent to which Indigenous research and methodologies have been developed to date in the business academy. Two decades ago, Shawn Wilson argued that "we now need to move beyond an Indigenous perspective in research" to "researching from an Indigenous paradigm" and that statement remains a challenge today. ${ }^{6}$ Progressing towards an Indigenous research paradigm has been limited by constraints that we will discuss in this article, specifically examining the use of a Pacific methodology within the business discipline.

This paper attempts to uncover the tensions Pacific early career academics encounter in promoting Pacific research methodologies such as talanoa in the business academy. We argue that this academy - a complex system reinforced by colonial power structures - is a site where resourcing, policy adjustments, and further research is required for the future of business research in Aotearoa to grow and for emerging local Oceanic talent to thrive. This paper attempts to unpack these issues with reference to our experiences as emerging Tongan academics in the business domain. We draw attention to the possible constraints in adopting Pacific methods such as talanoa, and offer insights to advance potential drivers to counter these limitations.

\section{Indigenous Research: Pacific Research Methodologies}

The dominant Western research paradigms in the business discipline include positivism, postpositivism, constructivism, action research, and critical theory. ${ }^{7}$ Although these paradigms can share some similarities with Indigenous methodologies, the distinct difference is that Indigenous methodologies specifically seek to ensure research that is culturally safe and respectful of Indigenous worldviews. It is crucial in ensuring Indigenous voices, culture, and identities are accurately represented. ${ }^{8}$ Prominent Tongan scholar Konai Helu Thaman suggests the power imbalance that exists through the domination of Western epistemologies and conscious subjugation of Pacific ways of constructing knowledges should be acknowledged. ${ }^{9}$

Pacific research methodologies involve Indigenous research that is conducted from the ontological and epistemological viewpoint of Pacific peoples. ${ }^{10}$ The 2018 New Zealand census identified seventeen Pacific peoples ethnic groups residing in New Zealand, with the largest ethnic groups being Tongan, Samoan, Cook Island, Fijian, Niuean, and Tokelauan. ${ }^{11}$ A majority of the published articles using Pacific research methodologies are located in the education, social work, and health disciplines. ${ }^{12}$ There are only a handful of studies within the business discipline that use Pacific research methodologies. ${ }^{13}$ Misatauveve Lupematasila Melani Anae provides a summary of current Pacific research methodologies in her work and the existing use of Pacific methodologies (such as talanoa, fa'afaletui, tivaevae and the vanua framework), demonstrating the significance of aligning the research process with the participants' ontology, epistemology, and axiology. ${ }^{14}$

Journal of New Zealand Studies NS33 (2021), 70-82 https://doi.org/10.26686/jnzs.iNS33.7383 
Although methodological choice is beneficial for researchers, the rapid increase in the presence and use of Indigenous research approaches has highlighted concerns around its theoretical underpinnings and critical grounding. ${ }^{15}$ Sanga and Reynolds highlight the importance of a more comprehensive and situated process to prevent confusion when developing new research approaches. ${ }^{16}$ This is important given that there are some overlapping values, practices, and theories across Pacific ethnic groups. Hence, careful consideration when developing Pacific methodologies will help to strengthen the overall Pacific research paradigm. One of the most developed and prevalent Pacific methodologies used to date is talanoa, which has Tongan origins but is a term Indigenous to many other Pacific ethnic groups and languages. In particular, talanoa is generally taken up in education, social work, and health disciplines, with only two studies published using talanoa in the business space. ${ }^{17}$ The primary Tongan research methodologies are talanoa, ${ }^{18}$ kakala, ${ }^{19}$ tauhi vă ${ }^{20}$ and tā-vā. ${ }^{21}$ For the purposes of this paper, we focus on talanoa from a business perspective to demonstrate its potential utility in business-oriented disciplines.

\section{Talanoa}

As demonstrated earlier, several Pacific scholars have written about culture-specific epistemologies, ontologies, and pedagogies in Pacific research. Although this has helped empower emerging Pacific researchers like us, little traction has been achieved in legitimising Pacific methods such as talanoa in the business discipline. Arguably, talanoa is the most prominent research methodology applied across the Pacific. ${ }^{22}$ It has also been used successfully by Pacific scholars to conduct research in other cultural contexts. ${ }^{23}$ For example, Samoan researcher Seuta'afili Patrick Thomsen used talanoa to examine race, racial hierarchy, and intercultural interactions through narratives of Korean gay men in Seoul. ${ }^{24}$ This emerging cross-cultural research demonstrates that talanoa is applicable beyond Pacific contexts and is an authoritative approach in its own right. This section attempts to review what is understood about the talanoa method, and pays particular attention to the ethics of applying talanoa in research.

Talanoa is rooted in oral traditions and is recognised in various island nations across the Pacific, including Fiji, Sāmoa, the Solomon Islands, Niue, the Cook Islands, and Tonga. ${ }^{25}$ Talanoa is a culturally appropriate methodology that is recognised for its sensitivity to Pacific contexts; it also enables meaningful engagement with research participants. Talanoa is a "dynamic interaction of story-telling, debating and reflecting." 26 Talanoa can often be reductively described as "sitting around the kava bowl" to informally discuss a predetermined topic with participants within a set of cultural protocols. ${ }^{27}$ Such framings can create misinterpretations that can be detrimental to the perception of talanoa as a legitimate method, and has facilitated the normalisation of "kava" as an ingredient for effective talanoa in the Tongan context.

Historically, underprivileged communities have not been afforded the same ethical considerations as Western communities. Ethical behaviour is not only governed by the researchers' institutional policies but also by the cultural underpinnings of the context under investigation. Pacific peoples' ethical behaviour is based on relationships individuals have with their god/s, land, and nature. ${ }^{28}$ As Tongan researchers, we lean on the four cultural values that embody Tongan identity, which are faka'apa'apa (respect), loto tō (humility), mamahi'i me'a (commitment and sacrifice), and feveitokai'aki (reciprocity). These core values are the foundations for how relationships are created 
and maintained, underpin actions and behaviours, and thus govern our conduct in the field. They are also the underlying principles that guide and inform our talanoa praxis.

Cultural protocols reflect the accepted norms of a society and are deemed a critical element that researchers should be aware of and understand before embarking on research. Margaret Kovach adds that "protocols are a means to ensure that activities are carried out in a manner that reflects community teachings and are done in a good way." 29 Unlike conventional Western methods, talanoa does not have a stringent process or particular way that it is administered. This is because different talanoa forms require various procedures and culturally accepted protocols. This is evident in different types of talanoa (pō/kalapu/talanoa; talanoa faikava) that encompass the consumption of kava and have their own formalities and traditional etiquettes. ${ }^{30}$

The ethics and cultural protocols that govern the talanoa process in research vary due to the variety of epistemological and ontological underpinnings of different Pacific cultures. As Tongan emerging researchers in the business academy, we subscribe to Tongan rituals and protocols for conducting talanoa; however, we often encounter tensions in situating the talanoa against Western methods to prove the legitimacy of our knowledge. Talanoa, from a Tongan perspective, has research protocols that aim to protect the integrity of participants, which is referred to as 'anga faka Tonga (Tongan way of being). There are five concepts that encompass 'anga faka Tonga: faka'apa'apa (respectful, considerate); anga lelei (tolerant, generous, kind, helpful, calm, dignified); mateuteu (well-prepared, culturally versed, responsive); poto he anga (knowing what to do and doing it well); and 'ofa feunga (empathy, love for the context/collective, compassionate). Researchers who adopt the talanoa method in the Tongan context are urged to embody these ideals in their conduct with participants in the field. ${ }^{31}$ There are some common cultural values that traverse diverse Pacific cultures, such as reciprocity, respect, and relationships. These values underscore the ethics and application of the talanoa regardless of context. We are not stating that specific talanoa traditions of each Pacific group are not valued or considered, but that these holistic principles build on the historical and genealogical relations that are shared across Pacific worlds, thus enabling Pacific researchers to craft and fashion their talanoa in ways that make sense to themselves and their participants.

\section{Constraints in Using Pacific Research Methodologies in Business}

Although there are key drivers for using Pacific research methodologies such as talanoa in business, there have also been constraints in advancing its use. We reflect on our experience as emerging Tongan academics in adopting talanoa in our respective disciplines to uncover the role that institutional and publication standards play in our decision to adopt Pacific methods.

Like many other emerging academics, we recognise that the epitome of an academic career is publishing. Although the publication process varies by discipline and by journals, a common factor is the high level of difficulty in publishing in more influential journals. Highly ranked mainstream journals in business are receptive to innovative and novel methodologies and methods. However, due to Indigenous research approaches being rare in business-oriented academic texts and published journal articles, they are often not perceived as valid. A handful of Indigenous scholars critique the process of legitimising localised methods against dominant Western epistemological and ontological frames as inconsistent with that which is being examined. ${ }^{32}$ Subdisciplines such as organisations studies-from which stems organisational behaviour research-focus on the

Journal of New Zealand Studies NS33 (2021), 70-82 https://doi.org/10.26686/jnzs.iNS33.7383 
nature of human interactions within organisational settings. These settings and contexts determine the methods adopted, however, because most influential journals privilege organisational samples from the United States and the white British Commonwealth; anything outside of this realm, in terms of intellectual/cultural knowledge, is considered an alternative perspective. For example, when we have submitted manuscripts using Pacific methods such as talanoa and the kakala framework, we have often received comments from editors suggesting that although contextually grounded, further work was required to highlight its utility outside of where it originated. Moreover, we have received infantilising and minimising critiques, which have referred to the flowers in the kakala framework, for example, as merely a nice ornament and decoration, implying its metaphorical application lacks theoretical rigour. These comments we take to be systemically racist; however, without Pacific senior scholars in business to cite, the burden of establishing Pacific presence in the canon falls on us as early career Pacific women.

Whilst it has been suggested that Pacific research methodologies and approaches are beginning to be accepted by an increasing number of publications, we note that these are often marginalised or viewed as secondary to the methodologies and approaches emerging from the dominant paradigm. This concern regarding marginalisation is evident when we acknowledge the extent to which our teaching and learning in business programs are based on dominantly held Western values, concepts, and approaches. These issues may be a result of the status of Pacific research methodologies that are still emerging; there are also perceptions that Indigenous research and approaches are too narrow and cannot be generalised. However, recent research by Indigenous scholars indicates that Indigenous knowledge from one population may be insightful and applicable or useful to understanding another population, and hence can be applied widely. ${ }^{33}$

These constraints limit the number of journals that will accept work using Pacific methodologies and approaches. Recent work by Loseto et al. has successfully addressed Indigenous involvement in peer review publications and the editorial process, in exploring the challenges of achieving equity in the research process. ${ }^{34}$ Hence, some work is starting to challenge these issues at the broader level that marginalises Indigenous research. Further to this, guest editors for the A* Journal of Management have recently drawn on their experiences as a large network of racially diverse scholars and concluded that racial biases express themselves in differential responses, and they have attributed this to research topics and research samples. ${ }^{35}$

Various scholars argue that the "academic pipeline" and institutional structures further perpetuate these hegemonic knowledge systems. The "academic pipeline" is often used to describe the progression of an individual through the academic ranks from undergraduate student to professor. It is also used in debates concerning equity and representation, and highlights where in the educational system minority students "leak." Sereana Naepi and colleagues examined the academic pipeline for Māori and Pacific graduates, highlighting the chronic underrepresentation of Māori and Pacific researchers in permanent academic positions in New Zealand universities. ${ }^{36}$ The authors identify three key factors that impede Māori and Pacific academics' progress in academia: excessive labour; precarity; and little support and guidance in developing key skills. Our experience of being Tongan academics in business-oriented disciplines in which there are only a handful of Pacific academics closely reflects these constraints. Excessive labour is particularly felt regarding the "invisible labour" we are subjected to, as it is assumed anything related to the

Journal of New Zealand Studies NS33 (2021), 70-82 https://doi.org/10.26686/jnzs.iNS33.7383 
Pacific is within our jurisdiction. These pressures lessen our capacity to contribute effectively and actively to legitimising our methods by way of publication.

Due to our training, we have fortunately developed specific skill sets that have enabled us to traverse multiple teaching, research, and service portfolios. Given the growing demand for the indigenisation of teaching and research in Aotearoa, many of our non-Pacific counterparts recognise the potential value we bring to our respective fields. This push to indigenise is mostly driven by the recent review of the Performance-Based Research Fund (PBRF) standards, which implored the tertiary education sector to promote the value of Indigenous and Pacific research. ${ }^{37}$ This recentring of values has provided more opportunities to foster new research relationships for Pacific researchers within our disciplines, and also in transdisciplinary ways. However, this opportunity also creates concerns about being confined to a tokenistic status within a research team. Given our strong ingrained cultural values as Tongans, reciprocation and maintaining relationships are important, but because of our values we often feel a sense of duty and obligation to take up every research opportunity that emerges. To navigate between our values and avoiding a tokenistic status, it has been crucial for us to thoroughly consider the research projects that we engage in to ensure we can contribute with our subject knowledge rather than merely being involved due to our sense of duty or for "representation" purposes, which highlights performative activism. Having a tokenistic role within a research team would contribute to limiting our capacity to work on progressing and legitimising our Pacific voices and methods through academic publications in the business discipline. Although it is not rare to see such experiences as tokenism, we argue that, in our context, these pressures further constrain our ability to meaningfully contribute and add value to advancing the agenda for validating Pacific research methods in our respective fields.

Notably, in the management domain, Eden et al. critiqued rigour and ethics and raised questions regarding the subjectivity of the peer review process. ${ }^{38}$ They argued that the same biases organisational scientists consider-such as confirmation bias, negative bias, anchoring and adjustment, overconfidence bias, and social dynamics - may affect the scholarship process. These biases are heightened for Pacific researchers, as anchoring and adjustment strategies are culturally specific, as are the institutions and disciplinary homes they occupy. In the foreground are neoliberal policies shaping resource distribution, and reward systems in universities that further disadvantage Pacific emerging researchers. Our unique position as two of only four Pacific academic staff in the business school requires us to develop strategies to negotiate and navigate the spaces we occupy. We are fortunate to have a growing network of Pacific emerging scholars that provides a safe space to work through common issues we encounter and share ways of progressing through academia, which has been immensely beneficial but has also made the gap between the experience of Pacific emerging researchers and non-Indigenous/non-Pacific emerging researchers more obvious.

Tyron Rakeiora Love recently provided a review of the emerging field of Indigenous organisational management scholarship and the powerful contributions Indigenous researchers have made in this growing domain. ${ }^{39}$ The emergence of this field is driven by the effects of colonisation and by attempts to reclaim traditional ways of researching, organising and managing. Indigenous scholars often seek asylum in more established critical and alternative fields of scholarship to generate research legitimacy. An important aspect to recognise is that disciplines

Journal of New Zealand Studies NS33 (2021), 70-82 https://doi.org/10.26686/jnzs.iNS33.7383 
such as management emerged from the United States, where most of our A-ranking journals are hosted. Organisational theory scholars typically see organisations as race-neutral bureaucratic structures, thus neglecting to consider alternative epistemic traditions outside of Eurocentric knowledge systems. A recent publication by Jacinta Ruru and Linda Waimarie Nikora highlight the many constraints facing Indigenous Māori academics when publishing their research. One of these issues is that only 5 percent of academic staff in Aotearoa are Māori. ${ }^{40}$ This results in an underrepresentation of Māori academics in universities, resulting in limited capacity to contribute and strengthen the presence of Māori research methodologies and methods. For Pacific, the percentage of our researchers as academic staff in Aotearoa sits even lower at 1.4 percent. ${ }^{41}$

This issue of under representation strongly applies to Pacific researchers in the business academy in Aotearoa. A lack of senior Pacific academics in the business school results in postgraduate students being trained in a solely Western research approach. As a result, any postgraduate students interested in using Pacific research approaches must seek expertise outside the business school. This limits access for students and staff to Pacific research methodologies and, therefore, limits the progression of Pacific research approaches within the business discipline. In addition, due to the limited capacity to address Pacific issues, we often go outside our faculty to seek professional advice and career guidance.

As noted by Dang et al., considerations and reflections on Indigenous academic experiences are concentrated in the fields of education, health and Indigenous studies, and are largely overlooked in the business scholarly domain. ${ }^{42}$ As stated above, a possible explanation for this is the very limited number of Indigenous scholars who occupy the business terrain. Internationally, there has been increasing attention to the underrepresentation of Indigenous peoples in tertiary education, as well as attempts to address it. ${ }^{43}$ Hence, the recruitment, retention, and progression of Indigenous academics is important in addressing this issue. ${ }^{44}$

\section{Pacific Research Methodologies in Business}

For Pacific researchers, cultural identity is intrinsic to our research approach. Cultural values, traditions, and belief systems are powerful and pervasive elements that inform research design and are vital foundations for methods that are representative of the research stakeholders we engage. This is evident in the emergence of ethnic-specific Pacific research frameworks that are based on culturally significant artefacts. These include the Samoan methodologies, ula and fa'afaletui, as well as the Fijian vanua framework. ${ }^{45}$ Inherent in methodological reform, these Pacific methodologies reset the power imbalance between researcher, academy, and participants. Research papers in the emerging field of Indigenous organisations and management are often shaped by the ideas of colonisation. Mostly, researchers seek to understand the detrimental colonial effects of domination and control on Indigenous peoples, resulting in efforts to challenge the prevailing institutions and ways of organising through decolonising agendas. Talanoa is an emancipatory research method that recentres the social and political freedoms and rights of participants.

Pacific and Indigenous researchers are driven by relationships that they have inherited genealogically, by association, or by virtue of proximity; these relationships form the basis of their identity. Thus, developing and sustaining meaningful relationships with research participants and other relevant research stakeholders is another driver for adopting Pacific methods such as talanoa. This has been our experience, as we have embraced talanoa as a mechanism to establish

Journal of New Zealand Studies NS33 (2021), 70-82 https://doi.org/10.26686/jnzs.iNS33.7383 
relationships with our participants. We have explored contentious topics such as foreign aid coordination strategies with donors and civil servants in Tonga, and talanoa was used specifically to develop relationships with participants so as to lessen the tension regarding the subject being discussed. Topics such as international aid effectiveness are often power-induced subjects and thus require the researcher to develop trust with the participants so as to enable them to feel comfortable to share their insights and experiences.

A business discipline that would benefit from the uptake and use of Pacific methods such as talanoa is family entrepreneurial studies. Family business presents a rich and nuanced context to apply the talanoa method, where the researcher and participants are actively exploring and co-constructing the knowledge. Semisi Prescott utilised talanoa to explore the business and accounting practices of Tongan business entrepreneurs in Aotearoa. ${ }^{46}$ The author emphasised the advantages of using talanoa over conventional interviewing methods as it allows the entrepreneur, the novice, to engage in co-constructing the content whilst allowing the researcher to delve deeper into topics of interest. Moreover, family business research often involves a small sample of participants, where researchers often find it difficult to avoid confidentiality issues. ${ }^{47}$ The talanoa method enables the researcher to develop trust-bearing relationships with participants that allow them to freely share their thoughts and concerns. Similarly, accounting and finance provide fruitful contexts in which researchers can adopt talanoa. Studies have found that accounting can have a detrimental role in the lives of Indigenous peoples, due to accounting services generally being provided by nonIndigenous peoples. ${ }^{48}$ However, there are opportunities to use talanoa to gain insights into Pacific peoples' accounting practices and the role of accounting in their financial wellbeing, because accounting can be an empowerment tool for Pacific peoples. For example, Pacific peoples often do not seek out financial advice services and consequently experience financial issues such as ongoing debt. ${ }^{49}$ Hence, the use of talanoa as a research method could contribute to expanding our limited knowledge of Pacific peoples' understanding, skills, attitudes, and behaviours around financial decision-making to develop effective programmes to aid Pacific peoples in making more informed financial decisions to prevent debt burden.

In the international business discipline, methodological contextualisation is an implicit component given that the phenomenon under investigation crosses national borders. ${ }^{50}$ Cross-cultural research requires culturally appropriate methods of data production. However, the treatment of culture in cross-cultural studies remains a critical issue, as fundamental concepts such as race and class in the societies in which the organisation is situated are omitted, framed as externalities, or rarely considered in theorisation. Some claim that for Indigenous researchers, "research is based on culture." ${ }^{51}$ However, culture has a delicate history for Indigenous peoples, and for researchers who travel across various contexts to engage their participants, Pacific methods such as talanoa can be applied across these multiple spaces to obtain authentic responses and develop meaningful relationships with participants. This was the case for one of the authors, who applied the talanoa method across multiple Pacific islands to gain insights into agricultural value chains. ${ }^{52}$ Common Pacific values such as reciprocity, respect, and collectivity were enacted in the Cook Islands, Niue, Sāmoa, and Tonga in the way talanoa was applied in these contexts. For instance, reciprocity was enacted at various stages of the research process, where a mea 'ofa or koha (gift) was presented to participants in the field and then again at the closure of the project by presenting the final results back to the government and community stakeholders (farmers, agricultural groups, and NGOs). This was not just in the form of a final report, but also in multilayered consultations at various

Journal of New Zealand Studies NS33 (2021), 70-82 https://doi.org/10.26686/jnzs.iNS33.7383 
levels to help socialise recommendations developed through the research. This level of community engagement in research requires time, effort, and carefully considered decisions to forge and strengthen community visibility and connection, and to develop cultural capital. Talanoa was used as a mechanism to draw on the insights and experiences of a range of participants from multiple Pacific islands in a respectful and culturally sensitive manner.

As conversations continue around the place of Indigenous knowledges in business, an area that is less traversed and provides future research directions is the interface between knowledge production and praxis, or actions that underpin practice. Amber Nicholson et al. explore the possibilities of bridging Indigenous and Western business practices and worldviews through ambicultural governance practices. ${ }^{53}$ Rather than highlighting the tensions between Western and Indigenous governance, the authors argue for the adoption of ambicultural governance practices that centre Indigenous tikanga while adjusting to hold with Western best practice. Weaving, a cultural tradition shared amongst many other Pacific Islands, was used as a central binding mechanism where each strand represented a paradigmatic component and features of kaupapa Māori. This type of theorisation opens the possibilities for Pacific methods to build and extend on the limitations of ambicultural governance practices. It also aids in the progress from incorporating Indigenous perspectives to researching from an Indigenous paradigm. This lesson would help to develop Pacific Indigenous research methods to the point of their being defined and delineated, rather than being compared and contrasted to Western research methodologies.

\section{Conclusion}

We examined the constraints and drivers to adopting talanoa in our respective fields to argue that institutional demands and limited Pacific capacity within the business space limits our ability to work towards legitimising talanoa and drive future-focused directions in research. These factors hinder our ability to actively contribute to the agenda of indigenising the business academy. Our paper cannot speak on behalf of all Pacific or Indigenous researchers, even within our own communities; however, it highlights some of the underlying principles, aspirations and challenges which are integral parts of Pacific research and knowledge production. An underlying constraint to advancing the legitimacy of talanoa in business is the perspective that Indigenous and Pacific knowledge systems are inferior to those that have arisen from imperialism. Another constraint is the very limited number of Pacific staff in the business school. As a pair, we are half the Pacific academic staff in the business school, and we are often stretched across multiple academic and service portfolios, leaving us very little capacity to advance the agenda of validating talanoa and Pacific research methods in our respective fields.

Literature on using Pacific research methodologies within the business discipline is still scarce compared to the progress made in other disciplines such as the arts, education, science, and health. However, in the business academic domain, both research and teaching, we believe, would benefit from utilising Pacific research methods to discover nuanced insights that are not possible with traditional Western research methodologies. Adopting contextualised methods leads to better quality theorisation that reflects the cultural values of the communities engaged in research. Thus, one of the drivers for adopting Pacific methods in business research is the opportunity to generate authentic localised theories for our communities. Contextualised theories go beyond their instrumentality and utility in the disciplinary discourse and further illuminate externalities as key characteristics that influence the phenomena under investigation. This framing signifies the

Journal of New Zealand Studies NS33 (2021), 70-82 https://doi.org/10.26686/jnzs.iNS33.7383 
importance of Pacific methods such as talanoa in generating theories that are consistent with the epistemological and ontological underpinnings of researched populations.

The key element of Pacific research is the cultural imperative for the Pacific researcher to know, acknowledge, and adhere to the ontology, axiology and epistemology that emerges from their own unique culture and traditions. It is a call for all researchers, Pacific or otherwise, to understand and own their own ontologies, axiologies, and epistemologies, rather than assuming that these are universal to all cultures across all time. As Pacific academics we have an important role to play in ensuring the visibility of Pacific peoples' experiences through our research, teaching and service. However, Eurocentric assumptions and expectations continue to undervalue our unique ways of being and doing, which undermines efforts to indigenise the academy. This paper ultimately argues that the business academy, a complex system reinforced by colonial power structures, is a site where resourcing, policy adjustments and further research is required for the future of business research in Aotearoa to thrive and for emerging local Oceanic talent to rise and thrive.

\footnotetext{
${ }^{1}$ Lisa Ellington, "Towards a Recognition of Plurality of Knowledge in Social Work: The Indigenous Research Paradigm," Canadian Social Work Review/Revue Canadienne de Service Social 36, no. 2 (2019): 29-48.

${ }^{2}$ Linda Tuhiwai Smith, Decolonizing Methodologies: Research and Indigenous Peoples (New York: St. Martin's Press, 1999).

${ }^{3}$ Courtney Ryder et al., "Indigenous Research Methodology-Weaving a Research Interface," International Journal of Social Research Methodology 23, no. 3 (2020): 255-67.

${ }^{4}$ Camilla Brattland, Britt Kramvig, and Helen Verran, "Doing Indigenous Methodologies: Toward a Practice of the "Careful Partial Participant,"” ab-Original: Journal of Indigenous Studies and First Nations and First Peoples' Cultures 2, no. 1 (2018): 74-96.

${ }^{5}$ Carl Urion, Ruth Norton, and Tom Porter, "Roundtable Discussion \#1," Canadian Journal of Native Education 21, supplement (1995): 55-60; Kabini Sanga, "Making Philosophical Sense of Indigenous Pacific Research," Researching the Pacific and Indigenous Peoples: Issues and Perspectives (2004): 4152.

${ }^{6}$ Shawn Wilson, "What is an Indigenous Research Methodology?" Canadian Journal of Native Education 25, no. 2 (2001): 175.

${ }^{7}$ Kathryn Roulston, "Considering Quality in Qualitative Interviewing," Qualitative Research 10, no. 2 (2010): 199-228; Yvonna S. Lincoln, Susan A. Lynham, and Egon G. Guba, "Paradigmatic Controversies, Contradictions, and Emerging Confluences, Revisited," The Sage Handbook of Qualitative Research 4, no. 2 (2011): 97-128.

${ }^{8}$ Olivia Sylvester and Alí García Segura, "Ulàpeitök: Using Bribri Indigenous Teachings to Develop a Ph.D. Research Methodology," Engaged Scholar Journal: Community-Engaged Research, Teaching, and Learning 3, no. 2 (2017): 123-40; Marlene Brant Castellano, "Ethics of Aboriginal Research," International Journal of Indigenous Health 1, no. 1 (2004): 98-114.

${ }^{9}$ Konai Helu Thaman, "Looking Towards the Source: A Consideration of (Cultural) Context in Teacher Education," in Proceedings of the Pacific Teacher Education Planning Meeting, 8-12 June (Suva: Institute of Education, USP, 1992), 3-13.

${ }^{10}$ Melani Anae, "Research for Better Pacific Schooling in New Zealand: Teu le Va-A Samoan perspective," MAI review 1, no. 1 (2010): 25.

${ }^{11}$ StatsNZ, "Pacific Peoples Ethnic Group," 2018, https://www.stats.govt.nz/tools/2018-census-ethnicgroup-summaries/pacific-peoples.
} 
${ }^{12}$ Anae "Research for Better Pacific Schooling in New Zealand"; Jacoba Matapo and Manutai Leaupepe, "A Duo-narrative of Pasifika Early Childhood Education: Reconceptualising Leadership in the Political and Social Landscape," Journal of Educational Leadership, Policy and Practice 31, no. 1/2 (2016): 5562; Kupa Kupa, "Te Vaka Atafaga: A Tokelau Assessment Model for Supporting Holistic Mental Health Practice with Tokelau People in Aotearoa, New Zealand," Pacific Health Dialog 15, no. 1 (2009): 15663; Sotiata Seiuli and Byron Malaela, "Meaalofa," New Zealand Journal of Counselling 30, no. 1 (2010): 47-63; Kiwi Tamasese et al., "Ole Taeao Afua, the New Morning: A Qualitative Investigation into Samoan Perspectives on Mental Health and Culturally Appropriate Services," Australian and New Zealand Journal of Psychiatry 39, no. 4 (2005): 300-09; Karlo Mila-Schaaf, "Va-centred Social Work: Possibilities for a Pacific Approach to Social Work Practice," Social Work Review 18, no. 1 (2006): 8; Jioji Ravulo, "Pacific Epistemologies in Professional Social Work Practice, Policy and Research," Asia Pacific Journal of Social Work and Development 26, no. 4 (2016): 191-202.

${ }^{13}$ Semisi M. Prescott, "Using Talanoa in Pacific Business Research in New Zealand: Experiences with Tongan Entrepreneurs," AlterNative: An International Journal of Indigenous Peoples 4, no. 1 (2008): 127-48; Sisikula S. P. Sisifa and Christina Stringer, "Relationships between International Buyers and Farmers: Insights from Tonga's Vanilla Industry," Academy of International Business Insights 21, no 1 (2021), DOI: $10.46697 / 001 c .19417$.

${ }^{14}$ Melani Anae, "Pacific Research Methodologies and Relational Ethics," in Oxford Research Encyclopedia of Education (2019), https://oxfordre.com/education; Vaoiva Ponton, "Utilizing Pacific Methodologies as Inclusive Practice," Sage Open 8, no. 3 (2018): 1-8.

${ }^{15}$ Greg Burnett, "Research Paradigm Choices Made by Postgraduate Students with Pacific Education Research Interests in New Zealand," Higher Education Research and Development 31, no. 4 (2012): 47992; Laumua Tunufa'i, "Pacific Research: Rethinking the Talanoa 'Methodology,"' New Zealand Sociology 31, no. 7 (2016): 227-39.

${ }^{16}$ Kabini Sanga and Martyn Reynolds, "To Know More of What It Is and What It Is Not: Pacific Research on the Move," Pacific Dynamics 1, no. 2 (2017): 198-204.

${ }^{17}$ Prescott, "Using Talanoa in Pacific Business Research in New Zealand"; Sisifa and Stringer "Relationships between International Buyers and Farmers."

${ }^{18}$ Mo'ale 'Otunuku, "How Can Talanoa Be Used Effectively an Indigenous Research Methodology with Tongan People?" Pacific-Asian Education 23, no. 2 (2011): 43-52; Semisi Manisela Prescott, "Pacific Business Sustainability in New Zealand: A Study of Tongan Experiences," (unpublished PhD dissertation: Auckland University of Technology, 2009); Timote M. Vaioleti, "Talanoa Research Methodology: A Developing Position on Pacific Research,” Waikato Journal of Education 12 (2006): 2134.

${ }^{19}$ Thaman, "Looking Towards the Source"; Seu'ula Johansson Fua, "Kakala Research Framework: A Garland in Celebration of a Decade of Rethinking Education," in Of Waves, Winds and Wonderful Things: A Decade of Rethinking Pacific Education, ed. Mo'ale 'Otunuku, Unaisi Nabobo-Baba, and Seu'ula Johansson Fua (Fiji: USP Press, 2014), 50-60; 'Ana Taufe'ulungaki et al., Sustainable Livelihood and Education in the Pacific: Tonga Pilot Report (Suva: Institute of Education, University of the South Pacific, 2007).

${ }^{20}$ Tevita Ka'ili, "Tauhi Vā: Nurturing Tongan Sociospatial Ties in Maui and Beyond," The Contemporary Pacific 17, no.1 (2005): 83-114; Tracie Mafile'o, "Tongan Social Work Practice," in Indigenous Social Work around the World: Towards Culturally Relevant Education and Practice, ed. Mel Gray, John Coates, and Michael Yellow Bird (Farnham, Ashgate, 2007), 121-34; Belinda 'Otukolo Saltiban, "Storying Academic Spaces: Reflections, Narratives, and Interpretations of Tongan Students' Educational Experiences" (unpublished PhD thesis: University of Utah, 2012).

${ }^{21}$ Hūfanga 'Ōkusitino Māhina, "TĀ, VĀ, and Moana: Temporality, Spatiality, and Indigeneity,” Pacific Studies 33, no. 2/3 (2010): 168-202. 
22 Trisia Farrelly and Unaisi Nabobo-Baba, "Talanoa as Empathic Apprenticeship," Asia Pacific Viewpoint 55, no. 3 (2014): 319-30.

${ }^{23}$ Patrick S. Thomsen, "Coming-Out in the Intersections: Examining Relationality in How Korean Gay Men in Seattle Navigate Church, Culture and Family through a Pacific Lens," Journal of Homosexuality 68, no. 6 (May 12, 2021): 1015-36.

${ }^{24}$ Patrick S. Thomsen, "Transnational Interest Convergence and Global Korea at the Edge of Race and Queer Experiences: A Talanoa with Gay Men in Seoul," Du Bois Review: Social Science Research on Race 17, no. 2 (2020): 1-18.

${ }^{25}$ Prescott, "Using Talanoa in Pacific Business Research in New Zealand."

26 'Otunuku, "How can Talanoa be used Effectively as an Indigenous Research Methodology with Tongan People?"

${ }^{27}$ Sanga and Reynolds, "To Know More of What It Is and What It Is Not."

${ }^{28}$ Johansson Fua, "Kakala Research Framework."

${ }^{29}$ Margaret Kovach, "Conversation Method in Indigenous Research," First Peoples Child and Family Review: An Interdisciplinary Journal Honouring the Voices, Perspectives, and Knowledges of First Peoples through Research, Critical Analyses, Stories, Standpoints and Media Reviews 5, no. 1 (2010): 41.

${ }^{30}$ Timote Vaioleti, "Talanoa, Manulua and Founga Ako: Frameworks for Using Enduring Tongan Educational Ideas for Education in Aotearoa/New Zealand" (unpublished PhD thesis: University of Waikato, 2010), https://hdl.handle.net/10289/5179.

${ }^{31}$ Johansson Fua, "Kakala Research Framework."

${ }^{32}$ Arun Agrawal, "Dismantling the Divide between Indigenous and Scientific Knowledge," Development and Change 26, no. 3 (1995): 413-39.

${ }^{33}$ Roxanne Struthers and Cynthia Peden-McAlpine, "Phenomenological Research among Canadian and United States Indigenous Populations: Oral Tradition and Quintessence of Time," Qualitative Health Research 15, no. 9 (2005): 1264-76; Lisa Loseto et al., "Indigenous Participation in Peer Review Publications and the Editorial Process: Reflections from a Workshop," Arctic Science 6, no. 3 (2020): 352-60.

${ }^{34}$ Loseto et al., "Indigenous Participation in Peer Review Publications and the Editorial Process."

${ }^{35}$ Derek R. Avery et al., "Racial Biases in the Publication Process: Exploring Expressions and Solutions," Journal of Management (July 2021), DOI: https://doi.org/10.1177/01492063211030561.

${ }^{36}$ Sereana Naepi et al., "The Pakaru 'Pipeline': Māori and Pasifika Pathways within the Academy," New Zealand Annual Review of Education 24 (2019): 142-59.

${ }^{37}$ Tyron R. Love and C. Michael Hall, "Understanding Indigenous Exploitation Through Performance Based Research Funding Reviews in Colonial States," Frontiers in Research Metrics and Analytics 5 (2020): 18.

${ }^{38}$ Eden B. King et al., "Systematic Subjectivity: How Subtle Biases Infect the Scholarship Review Process," Journal of Management 44, no. 3 (2018): 843-53.

${ }^{39}$ Tyron R. Love, "Indigenous Knowledge, Priorities and Processes in Qualitative Organization and Management Research: State of the Field," Qualitative Research in Organizations and Management 15 (2020): 6-10.

${ }^{40}$ Jacinta Ruru and Linda W. Nikora, Ngā Kete Mātauranga. Māori Scholars at the Research Interface (Dunedin: Otago University Press, 2021).

${ }^{41}$ Naepi et al., "The Pakaru 'Pipeline.': Māori and Pasifika Pathways within the Academy."

${ }^{42}$ Thi Kim Anh Dang et al., "Improving the Participation and Engagement of Aboriginal and Torres Strait Islander Students in Business Education," Journal of Higher Education Policy and Management 38, no. 1 (2016): 19-38. 
${ }^{43}$ Christine Asmar and Susan Page, "Pigeonholed, Peripheral or Pioneering? Findings from a National Study of Indigenous Australian Academics in the Disciplines," Studies in Higher Education 43, no. 9 (2018): 1679-91; Dang et al., "Improving the Participation and Engagement of Aboriginal and Torres Strait Islander Students in Business Education"; Jack Frawley, Steve Larkin, and James A. Smith, "Indigenous Pathways and Transitions into Higher Education: An Introduction," in Indigenous Pathways, Transitions and Participation in Higher Education, ed. Jack Frawley, Steve Larkin, and James A. Smith (Singapore: Springer, 2017), 3-11.

${ }^{44}$ Dang et al., "Improving the Participation and Engagement of Aboriginal and Torres Strait Islander Students in Business Education"; Gregory Martin, Vicky Nakata, Martin Nakata, and Andrew Day, "Promoting the Persistence of Indigenous Students through Teaching at the Cultural Interface," Studies in Higher Education 42, no. 7 (2017): 1158-73; Joanna Kidman and Cherie Chu, "We're not the Hottest Ethnicity': Pacific Scholars and the Cultural Politics of New Zealand Universities," Globalisation Societies and Education 17, no. 1 (2019): 1-11.

${ }^{45}$ Seiuli Luama Sauni, "Samoan Research Methodology: The Ula-A New Paradigm," Pacific-Asian Education Journal 23, no. 2 (2011): 53-63; Tamasailau Suaalii-Sauni and Saunimaa Ma Fulu-Aiolupotea, "Decolonising Pacific Research, Building Pacific Research Communities and Developing Pacific Research Tools: The Case of the Talanoa and the Faafaletui in Samoa," Asia Pacific Viewpoint 55, no. 3 (2014): 331-44; Unaisi Nabobo-Baba, Knowing and Learning: An Indigenous Fijian Approach (Suva: University of the South Pacific, 2006).

${ }^{46}$ Prescott, "Using Talanoa in Pacific Business Research in New Zealand."

${ }^{47}$ Tyge Payne and Duane Ireland, "It Takes a Village: Ethical Publishing of Family Business Research," Family Business Review 28, no. 2. (2015): 96-103.

${ }^{48}$ Nola Buhr, "Indigenous Peoples in the Accounting Literature: Time for a Plot Change and Some Canadian Suggestions," Accounting History 16, no. 2 (2011): 139-60; Luisa Lombardi,

"Disempowerment and Empowerment of Accounting: An Indigenous Accounting Context," Accounting, Auditing and Accountability Journal 29, no. 8 (2016): 1320-41.

${ }^{49}$ Gaur. S. Sanjaya et al., "Consumption of Financial Products amongst Vulnerable Pacific Island People in New Zealand," Journal of Consumer Marketing 37, no 7 (2020): 833-42.

${ }^{50}$ Snejina Michailova, "Contextualizing in International Business Research: Why Do We Need More of It and How Can We Be Better at It?" Scandinavian Journal of Management 27, no. 1 (2011): 129-39.

${ }^{51}$ Shaun Awatere et al., "Whakatipu Rawa Ma ngā Uri Whakatipu: Optimising the "Māori" in Māori Economic Development," AlterNative: An International Journal of Indigenous Peoples 13, no. 2 (2017): 82.

${ }^{52}$ Sisifa and Stringer, "Relationships between International Buyers and Farmers."

${ }^{53}$ Amber Nicholson, Chellie Spiller, and Edwina Pio, "Ambicultural Governance: Harmonizing Indigenous and Western Approaches,” Journal of Management Inquiry 28, no. 1 (2019): 31-47. 